\title{
Effect of Gold on the Adsorption Properties of Acetaldehyde on Clean and h-BN Covered Rh(111) Surface
}

\author{
Arnold Péter Farkas $^{1,2}$ · Ádám Szitás ${ }^{3} \cdot$ Gábor Vári $^{3} \cdot$ Richárd Gubó $^{2,3}$ • László Óvári ${ }^{1,2}$ • András Berkó ${ }^{1}$ · János Kiss ${ }^{1,4}$. \\ Zoltán Kónya ${ }^{1,3}$
}

Published online: 11 May 2018

C Springer Science+Business Media, LLC, part of Springer Nature 2018

\begin{abstract}
Auger electron spectroscopy, high-resolution electron energy loss spectroscopy and temperature programmed desorption methods have been used in order to investigate the adsorption properties and reactions of acetaldehyde on gold decorated rhodium and $\mathrm{BN} / \mathrm{Rh}(111)$ surfaces. Scanning tunneling microscopy and X-ray photoelectron spectroscopy measurements were carried out to characterize the gold nanoparticles on clean and hexagonal boron nitride (h-BN) covered $\mathrm{Rh}(111)$. The adsorption of acetaldehyde was not completely hindered by gold atoms; however, depending on the structure of the outermost bimetallic layer (surface alloy) the dissociation of the parent molecule was suppressed, namely the production of carbon monoxide was inhibited by the gold domains. Our measurements with acetaldehyde on Au/h-BN/Rh(111) confirmed the observation that the lack of suitable adsorption sites eliminates the formation of CO. Nevertheless, increased coverage of gold enhanced the amount of adsorbed aldehyde at low temperature. We may predict that the low reactivity of acetaldehyde on $\mathrm{Au} / \mathrm{h}-\mathrm{BN} / \mathrm{Rh}(111)$ significantly determine the ethanol decomposition mechanism on this surface.
\end{abstract}

Keywords Acetaldehyde $\cdot$ Polymerization $\cdot \operatorname{Rh}(111) \cdot$ Boron nitride $\cdot$ Effect of gold $\cdot$ HREELS

\section{Introduction}

Chemisorbed aldehyde has been proposed as key intermediate, an important surface and gas-phase product in the decomposition of primary alcohols (e.g.: catalytic steam reforming of ethanol) on metal surfaces [1-6]. Besides the environmental protection aspects $[7,8]$ this is the motivation which places the acetaldehyde chemistry in the focus of catalytic community. Noble metals, including Rh, proved

Arnold Péter Farkas

arnold.farkas@chem.u-szeged.hu

1 MTA-SZTE Reaction Kinetics and Surface Chemistry Research Group, University of Szeged, Dóm tér 7, Szeged 6720, Hungary

2 Extreme Light Infrastructure-ALPS, ELI-HU Non-profit Ltd., Dugonics tér 13, Szeged 6720, Hungary

3 Department of Applied and Environmental Chemistry, University of Szeged, Aradi Vértanúk tere 1, Szeged 6720, Hungary

4 Department of Physical Chemistry and Materials Science, University of Szeged, Rerrich Béla tér 1, Szeged 6720, Hungary to be excellent catalysts for the dehydrogenation of ethanol [9-13].

It is generally accepted that acetaldehyde bound in an $\eta^{2}(\mathrm{C}, \mathrm{O})$ configuration on unsupported well-defined $\mathrm{Pt}$ metal surfaces [14-17]. $\eta^{2}-\mathrm{CH}_{3} \mathrm{CHO}_{\mathrm{a}}$ decomposes to adsorbed products; $\mathrm{CH}_{2} \mathrm{CO}_{\mathrm{a}}, \mathrm{CH}_{3}, \mathrm{CH}_{2}, \mathrm{CH}, \mathrm{H}_{\mathrm{a}}, \mathrm{CO}_{\mathrm{a}}$ and carbon. $\mathrm{CO}$ and $\mathrm{H}_{2}$ are the final products in the gas phase. Gold-based classical high surface area catalysts have widely investigated for oxidation and hydrogenation reactions, but fundamental studies on model catalysts are lacking. Acetaldehyde partial oxidation on the $\mathrm{Au}(111)$ model catalyst surface via $\mathrm{C}-\mathrm{C}$ bond activation occurs and formation of methyl acetate as an oxidative coupling product forms. Hydrogenation of aldehyde to ethanol was attempted by temperature programmed desorption (TPD) and density functional theory calculation (DFT) on $\mathrm{Au}(111)$ [18-20].

In the present work we aimed to investigate the surface chemistry of acetaldehyde on well-defined gold nanoparticles. It is well established that Au clusters supported on various metal oxides show strong catalytic activity for a wide variety of reactions. The most dramatic and wellknown factor known to influence the catalytic activity of such systems is the size and shape of the Au nanoparticles 
[21-24]. The other important factor is the metal-support interaction which could basically influence the efficiency of the catalyst and so Au catalysts can almost never be considered independently from the support.

At present, two non-oxide supports are studied where the metal support interaction could be minimized. Graphene is in the focus of research and it is suitable to control the growth of metal including gold [25-27]. The other inert support is the boron-nitride prepared on single crystal surfaces. Hexagonal boron nitride (h-BN) on transition metal surfaces is free of oxygen and can help avoid ambiguities in the interpretation of the nature of active sites on Au nanocatalysts. Particularly interesting is the $\mathrm{h}-\mathrm{BN} / \mathrm{Rh}(111)$ system, especially since the discovery of a self-organized boron nitride superstructure on a $\mathrm{Rh}(111)$ surface by Corso et al. [28]. BN grows in a nanomesh form because of the stronger interfacial chemical bonding as a consequence of better orbital overlapping. The growth of $\mathrm{Au}$ and the surface properties of the formed gold nanoparticles were investigated by different surface science tools [28-34]. Scanning tunneling microscopy (STM) and low energy ion scattering (LEIS) measurements confirmed that at small coverages up to $\Theta_{\mathrm{Au}}=0.1-0.2 \mathrm{ML}$, nearly two dimensional clusters form, while a clearly $3 \mathrm{D}$ growth was found at higher gold doses. Au nanoparticles nucleate preferentially at the pore-wire interface. Low temperature metal deposition yielded smaller clusters. X-ray photoelectron spectroscopy (XPS) analysis of core-level electronic states in the deposited Au shows strong finalstate effects induced by restricted size dominating for low coverage [32, 35]. DFT calculation supports that all $\mathrm{Au}$ atoms in these one monolayer high clusters are negatively charged [31]. At higher coverages, the Au nanoparticles are less negatively charged; in particularly, topmost layer gold atoms are almost neutral [32]. Annealing the Au/h$\mathrm{BN} / \mathrm{Rh}(111)$ surface to higher temperatures resulted in the intercalation of Au below the h-BN layer according to LEIS, which is complete at $1050 \mathrm{~K}$ [35]. Desorption and agglomeration of Au also takes place.

In this work we studied the adsorption of acetaldehyde on Au covered Rh(111) and h-BN/Rh(111) surfaces. The stability and reactivity of adsorbed acetaldehyde is monitored by TPD and high-resolution electron energy loss spectroscopy (HREELS). This study is in connection with establishing of the reaction mechanism of ethanol transformation on the above mentioned, quasi inert surfaces. When different oxides are the support for gold, the ethanol decomposition runs differently further forming methane, ethane, hydrogen and CO [36]. The knowledge of the reactivity of acetaldehyde on Au covered h-BN/Rh(111) surface may give an answer to these differences and it is possible to investigate the reactivity of these nanoparticles with a lowest support impact.

\section{Experimental}

Three UHV systems were applied in these studies. The operation of the first system was described previously [33]. In this two-level UHV chamber the routine base pressure of $5 \times 10^{-10}$ mbar produced by a turbomolecular pump. It was equipped with facilities for auger electron spectroscopy (AES), HREELS and TPD. The HREEL spectrometer (LK, ELS 3000) is situated in the lower level of the chamber, and has a resolution of $20-40 \mathrm{~cm}^{-1}$ (FWHM). The count rates in the elastic peak were typically in the range of $1 \times 10^{4}-1 \times 10^{5}$ counts per second (cps). All spectra reported were recorded with primary beam of $6.5 \mathrm{eV}$ and at an incident angle of $60^{\circ}$ with respect to the surface normal in the specular direction. A Balzers QMS was used for TPD situated close to the surface normal. $4 \mathrm{~K} \mathrm{sec}^{-1}$ heating rate was used in these measurements.

The second one was equipped with a commercial room temperature (RT) scanning tunneling microscope (WATechnology), a cylindrical mirror analyzer with a central electron gun (Staib-DESA-100), and a quadrupole mass spectrometer (Balzers-Prisma). Note that, in this work, AES and mass spectrometry (MS) techniques were mainly applied for checking the surface/ad-metal cleanliness and the gas phase composition. STM images of $256 \times 256$ pixels were generally recorded in constant current mode at a bias of $-1.0 \mathrm{~V}$ on the sample and a tunneling current of $0.1 \mathrm{nA}$. W tips were applied in the course of the experiments. The conditioning of the tip was a relatively simple procedure: several seconds at $+3 \mathrm{~V}$ and $10 \mathrm{nA}$. The constant current (cc) morphology images are shown in top-view representation, where brighter areas correspond to higher $\mathrm{Z}$ values. Images of enhanced lateral resolution were recorded in constant height (ch) mode, where the local-dependent variation of tunneling current (no feedback) served for construction of the image. In the case of some high resolution images, a gentle fast Fourier transformation (FFT) treatment was also applied.

In the third system a hemispherical electron energy analyzer (Leybold Heraeus) was used for XPS, AES and LEIS. An $\mathrm{Al} \mathrm{K}$ X-ray source was applied for XPS, performed with constant pass energy. The binding energy scale was calibrated against the $4 \mathrm{f}_{7 / 2}$ peak of a thick Au layer, fixed at $84.0 \mathrm{eV}$ and the $3 \mathrm{~d}_{5 / 2}$ peak of the Rh single crystal, fixed at $307.2 \mathrm{eV}$. The detection angle was $16^{\circ}$ with respect to the surface normal. For LEIS He${ }^{+}$ions of $800 \mathrm{eV}$ kinetic energy were used, and the scattering angle was $95^{\circ}$. The probe was radiatively heated by a $\mathrm{W}$ filament placed behind the sample. Its temperature was measured with a chromel-alumel (K-type) thermocouple spot welded to the side of the sample.

The $\mathrm{Rh}(111)$ crystal used in these works was cut from single crystal boule and was a product of Materials 
Research Corporation (purity 99,99\%). Initially, the samples were cleaned by repeated $\mathrm{Ar}^{+}$sputtering (typically $1 \mathrm{kV}, 1 \times 10^{-7} \mathrm{mbar}$ and $2 \mu \mathrm{A}$ for $10-30 \mathrm{~min}$ ) and annealing to $900-1100 \mathrm{~K}$ until no contamination were detected by AES. The sample was heated resistively from 140 to $1200 \mathrm{~K}$ in HREEL chamber. Acetaldehyde $\left(\mathrm{CH}_{3} \mathrm{CHO}\right)$ of 99\% purity was the product of Sigma Aldrich. It was purified by several freeze-pump-thaw cycles and for adsorption it was dosed through a capillary which was ca. $1.5 \mathrm{~cm}$ from the sample.

Au was deposited by a commercial physical vapor deposition (PVD) source (Oxford Applied Research) using highpurity $(99.95 \%)$ Au. The coverage of gold is expressed in monolayer equivalent (MLE), defined as the surface concentration of $\mathrm{Rh}(111): 1.60 \times 10^{15} \mathrm{~cm}^{-2}$ [37]. In all cases the evaporation rate was $\sim 0.2 \mathrm{MLE} \mathrm{min}^{-1}$.

Monolayer of h-BN was prepared at $1000-1050 \mathrm{~K}$ via thermal decomposition of $>99.8 \%$ purity borazine, a product of Katchem Ltd.

\section{Results and Discussion}

\subsection{Adsorption and Decomposition of Acetaldehyde on Clean and Gold Decorated Rh(111)}

In our previous study we investigated the adsorption properties of acetaldehyde on clean $\mathrm{Rh}(111)$ surface [17]. Adsorption of acetaldehyde at $\sim 120 \mathrm{~K}$ produced various types of adsorption forms: $\eta^{1}-(\mathrm{O})-\mathrm{CH}_{3} \mathrm{CHO}$ and $\eta^{2}-(\mathrm{O}, \mathrm{C})-\mathrm{CH}_{3} \mathrm{CHO}$ were developed and characterized by HREELS. $\eta^{1}-(\mathrm{O})$ $\mathrm{CH}_{3} \mathrm{CHO}$ desorbed at $150 \mathrm{~K}$, another part of these species are incorporated in trimer, linear 2D polymer and threedimensional surface species. Above $225 \mathrm{~K}$ acetaldehyde either desorbed (in monomer and trimer forms) or bonded as a stable surface intermediate $\left(\eta^{2}-(\mathrm{O}, \mathrm{C})-\mathrm{CH}_{3} \mathrm{CHO}\right)$ on the rhodium surface. It was the first observation of the polymerization process of acetaldehyde on $\mathrm{Rh}(111)$ [17]. The surface intermediates at higher temperature decomposed to $\mathrm{CO}, \mathrm{H}_{\mathrm{a}}, \mathrm{CH}_{4}$ and surface carbon. In our first experiment in this study we adsorbed acetaldehyde on the clean rhodium surface (Fig. 1.) to have base comparison spectra before we investigate the gold decorated substrate. We adsorbed $\sim 10 \mathrm{~L}$ of acetaldehyde at $170 \mathrm{~K}$ on the clean $\mathrm{Rh}(111)$ single crystal. At $\sim 170 \mathrm{~K}$, we observed peaks at $430,610,920,1120,1460$ and at $\sim 3000 \mathrm{~cm}^{-1}$ characteristic to adsorbed acetaldehyde molecule. Increasing the temperature to $200 \mathrm{~K}$, we recognize small shifts in peak positions and new peaks appear at $650,750,1180$ and $1560 \mathrm{~cm}^{-1}$. Small downward shifts also occurred for the loss at $\sim 1100 \mathrm{~cm}^{-1}$. Similarly to our former observation the features in HREELS at $200 \mathrm{~K}$, originates from the formation of surface oligomers and the peaks mentioned above belong to $\mathrm{O}-\mathrm{C}-\mathrm{O}$ vibrations (see Table 1.). The

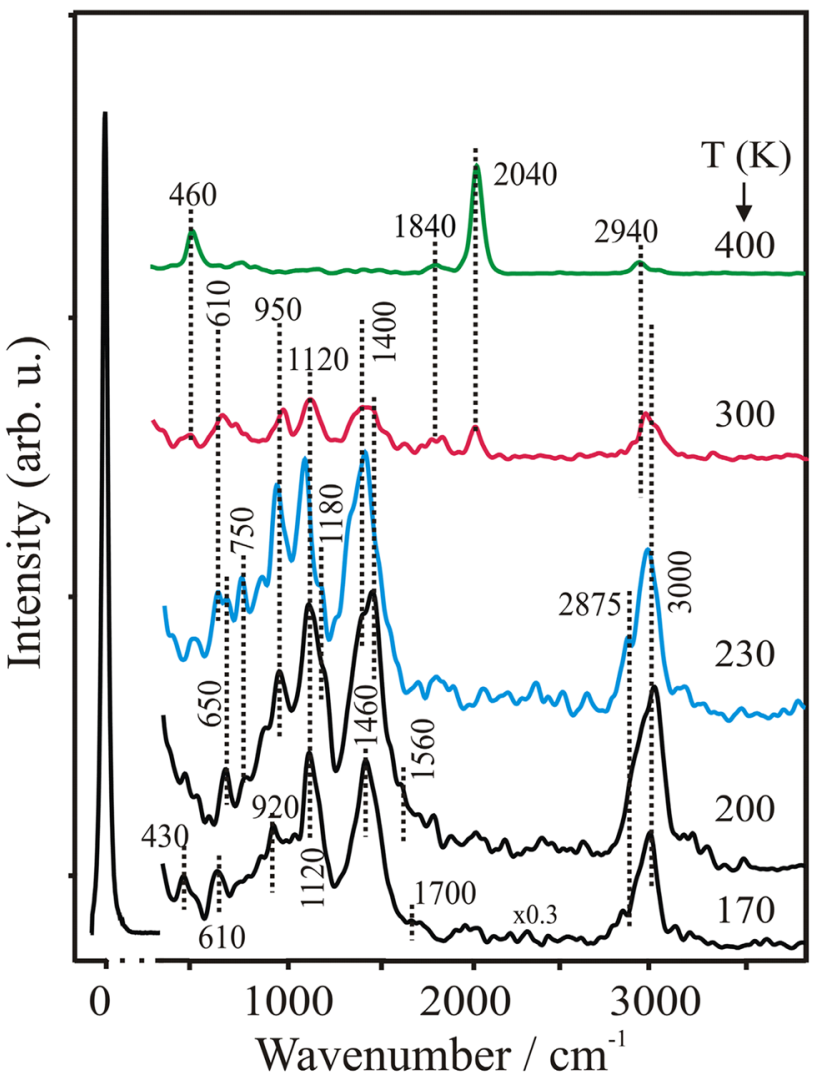

Fig. 1 HREEL spectra of adsorbed $\mathrm{CH}_{3} \mathrm{CHO}$ at $170 \mathrm{~K}$ on the clean $\mathrm{Rh}(111)$ surface followed stepwise annealing at different temperatures

losses connected to $\eta^{2}(\mathrm{C}, \mathrm{O})$-acetaldehyde at low exposure (790, 1270, 1460 and $~ 2800 \mathrm{~cm}^{-1}$ ) are missing. Upon heating the layer above $230 \mathrm{~K}$, the peaks at 650 and $1180 \mathrm{~cm}^{-1}$ disappeared from the spectra. Nevertheless, all of the peaks were attenuated at $300 \mathrm{~K}$, although they are still discernible at $610,950,1120,1400$ and $2940 \mathrm{~cm}^{-1}$. These features can be attributed to different hydrocarbon fragments. At the same time, $\mathrm{CO}$ surface vibrations as new peaks appeared at $460, \sim 1800$ and at $2040 \mathrm{~cm}^{-1}$; however, the hydrocarbon species still dominated the spectra at $300 \mathrm{~K}$. The $\mathrm{CO}$ losses are the clear sign that acetaldehyde started to dissociate to $\mathrm{CO}, \mathrm{CH}_{\mathrm{x}}$ and $\mathrm{H}_{\mathrm{a}}$ on the surface. At $400 \mathrm{~K}$ only the peaks characteristic to $\mathrm{CO}$ adsorption were observed; at the next temperature step, above $500 \mathrm{~K}$, all peak disappeared from the spectra (not shown).

Following the measurements on clean $\mathrm{Rh}(111)$ surface, similar experiments were also performed on $~ 0.5$ MLE gold modified surface. In this case the Au was deposited at $500 \mathrm{~K}$ in order to eliminate carbon monoxide adsorption from the background and to prevent the surface mixing of $\mathrm{Au}$ and $\mathrm{Rh}$ [37]. The morphology STM image of $45 \times 45 \mathrm{~nm}^{2}$ is shown in Fig. 2a, where the Au islands marked on the image form well separated 2D plates on the $\mathrm{Rh}(111)$ terraces or they can be condensed to $\mathrm{Rh}$ atomic steps (step flow growth mode) 
Table 1 Characteristic vibrations of acetaldehyde on single crystal surfaces

\begin{tabular}{|c|c|c|c|c|c|c|c|c|}
\hline $\begin{array}{l}\text { Vibrational } \\
\text { mode }\end{array}$ & $\begin{array}{l}\text { Crystalline } \\
\mathrm{CH}_{3} \mathrm{CHO} \text { [38] }\end{array}$ & $\begin{array}{l}\mathrm{CH}_{3} \mathrm{CHO} \\
\text { on } \mathrm{Ru}(001) \\
\text { at } 300 \mathrm{~K}[14]\end{array}$ & $\begin{array}{l}\eta^{1}(\mathrm{O})- \\
\mathrm{CH}_{3} \mathrm{CHO} \text { on } \\
\mathrm{Pt}(111) \text { at } \\
90 \mathrm{~K}[39]\end{array}$ & $\begin{array}{l}\eta^{2}(\mathrm{C}, \mathrm{O})- \\
\mathrm{CH}_{3} \mathrm{CHO} \text { on } \\
\mathrm{Rh}(111)[16]\end{array}$ & $\begin{array}{l}10 \mathrm{~L} \mathrm{CH}_{3} \mathrm{CHO} \\
\text { on } \mathrm{Rh}(111) \\
\text { at } 200 \mathrm{~K}[40]\end{array}$ & $\begin{array}{l}\text { Ketene }+\mathrm{H} \\
\text { on } \mathrm{Ru}(001) \\
\text { at } 250 \mathrm{~K}[41]\end{array}$ & $\begin{array}{l}\text { Present study } \\
\text { on gold/ } \\
\mathrm{Rh}(111) \\
\text { at } 300 \mathrm{~K}\end{array}$ & $\begin{array}{l}\text { Present study } \\
\text { on gold/rho- } \\
\text { dium alloy } \\
\text { at } 300 \mathrm{~K}\end{array}$ \\
\hline$\nu_{\mathrm{a}}\left(\mathrm{CH}_{3}\right)$ & 2980 & & 2984 & & & 3025 & & \\
\hline$\nu_{\mathrm{s}}\left(\mathrm{CH}_{3}\right)$ & 2930 & 2955 & & 2980 & 3000 & 2930 & 2970 & 2990 \\
\hline$\nu(\mathrm{CH})$ & 2905 & 2740 & & & 2875 & 2755 & 2890 & \\
\hline$\nu(\mathrm{CO})$ & & $\mathrm{nr}$ & 1667 & 1460 & 1460 & 1275 & 2030 & \\
\hline$\delta_{\mathrm{a}}\left(\mathrm{CH}_{3}\right)$ & 1443,1400 & & 1430 & & 1400 & & 1420 & 1450 \\
\hline$\delta_{\mathrm{s}}\left(\mathrm{CH}_{3}\right)$ & 1385,1347 & 1365 & 1365 & 1380 & & 1365 & 1340 & \\
\hline$\nu_{\mathrm{a}}(\mathrm{OCO})$ & $\begin{array}{l}1187,1158 \\
1122\end{array}$ & & & & 1560 & & 1590 & \\
\hline$\nu_{\mathrm{s}}(\mathrm{OCO})$ & 1083,1040 & & & & 1180 & & 1195 & \\
\hline$\nu(\mathrm{CC})$ & na & 1105 (nr) & 1130 & 1135 & 1120 & 1135 & 1080 & \\
\hline$\rho\left(\mathrm{CH}_{3}\right)$ & 973,933 & 970 & 913 & 950 & 950 & 975 & 930 & \\
\hline$\delta(\mathrm{CH})$ & 850,835 & 755 & & & 750 & 795 & 750 & 850 \\
\hline$\delta(\mathrm{OCO})$ & & & & & 650 & & 640 & \\
\hline$\delta(\mathrm{CCO})$ & na & 675 & 607 & 610 & & 655 & & 610 \\
\hline$\pi(\mathrm{CCO})$ & & & & & & 575 & & \\
\hline
\end{tabular}
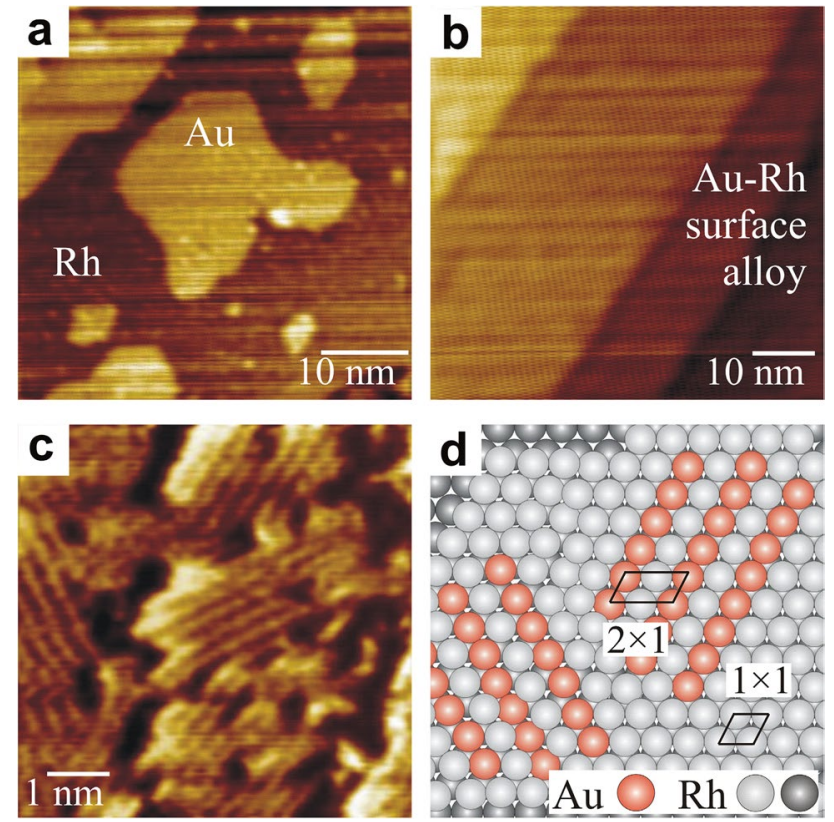

Fig. 2 STM cc-images detected a on 0.5 MLE gold deposited $\left(\mathrm{T}_{\mathrm{d}}=500 \mathrm{~K}\right)$ and $\mathbf{b}$ subsequently annealed $(1000 \mathrm{~K}, 5 \mathrm{~min}) \mathrm{Rh}$ (111) surfaces. c High resolution STM ch-image of $5 \times 5 \mathrm{~nm}^{2}$ taken on atomic terraces shown in b. d Schematic model concerning the ordered $(1 \times 2) \mathrm{Au}-\mathrm{Rh}$ alloy phase

[37]. This type of growth mode suggests that in this state relatively large clean rhodium terraces of the $\mathrm{Rh}(111)$ surface are also available. Using this sample, the acetaldehyde was exposed at $T_{a}=170 \mathrm{~K}$. The HREEL spectra of acetaldehyde recorded after preadsorption of gold shows similar features as on the clean $\mathrm{Rh}$ surface at low temperature (Fig. 3a). Increasing the temperature of the adsorbed layer we observed several characteristic vibrations of $\eta^{2}-(\mathrm{O}, \mathrm{C})$ $\mathrm{CH}_{3} \mathrm{CHO}$ at $640,750,930,1080,1125,1195,1340,1420$, 2890 and $2970 \mathrm{~cm}^{-1}$ in harmony with the work by Houtman and Barteau [16] and similarly to the results on $\mathrm{Ru}(0001)$ at $300 \mathrm{~K}$ [14]. However, the peaks at 640 and the shoulder at $1590 \mathrm{~cm}^{-1}$ at RT could be also the sign of surface oligomer formation, they belong very likely to the $\delta(\mathrm{OCO})$ and $\nu_{\mathrm{a}}(\mathrm{OCO})$ modes, respectively [17]. Based on these results, we cannot rule out the interaction between neighboring $\eta^{1}$ (O)- $\mathrm{CH}_{3} \mathrm{CHO}$ molecules, the production of oligomers or polymers. The very intensive peak at $2030 \mathrm{~cm}^{-1}$ at RT can be assigned to the formation of $\mathrm{CO}$ in on top position and there is no doubt that these molecules originated from the dissociation of $\eta^{2}$-acetaldehyde connected to rhodium atoms. Above $300 \mathrm{~K} \mathrm{CO}$ is not stable on gold. This statement is based not only on literature data but also on our own test measurements (not shown). Another remarkable finding is that on gold decorated surface the $\mathrm{CO}$ peak is the dominant loss already at $300 \mathrm{~K}$ and no contribution observed at around $1860 \mathrm{~cm}^{-1}$.

In the subsequent part of this work we present similar acetaldehyde adsorption measurements as above on a $\mathrm{Rh}-\mathrm{Au}$ alloy surface containing also approximately 0.5 MLE gold. The recipe is taken from our former work, in which the gold growth and surface alloying were studied in detail on $\mathrm{Rh}(111)$ surface [37]. Figure 2b shows an STM image of $50 \times 50 \mathrm{~nm}^{2}$ recorded on gold ( 0.5 MLE at $\left.500 \mathrm{~K}\right)$ deposited $\mathrm{Rh}(111)$ surface after annealing it at $1000 \mathrm{~K}$ for $5 \mathrm{~min}$. As it was demonstrated in [37], following the higher 
Fig. 3 a HREEL spectra of adsorbed $\mathrm{CH}_{3} \mathrm{CHO}$ at $170 \mathrm{~K}$ and the subsequent annealing at higher temperatures a on a 0.5 ML gold decorated $\mathrm{Rh}(111)$ surface shown in Fig. 2a. b On the Au-Rh alloy surface shown in Fig. $2 b$
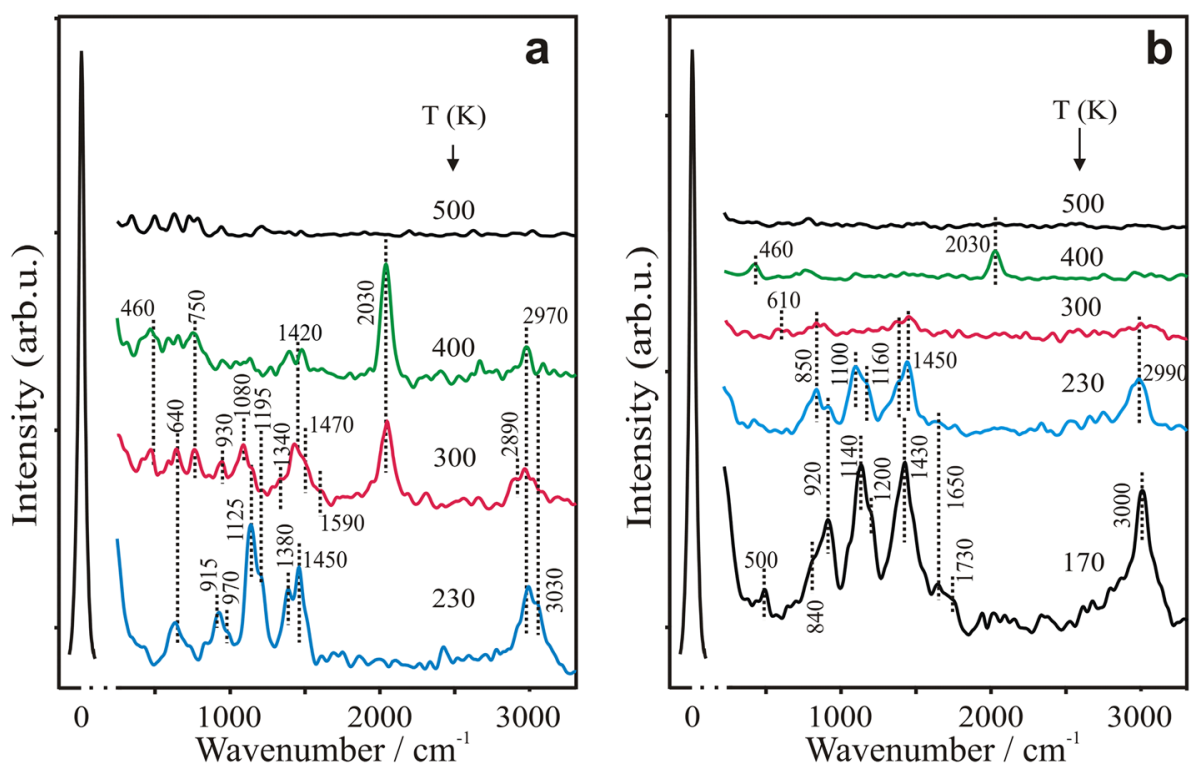

temperature $(\mathrm{T}>700 \mathrm{~K})$ treatment, these bulk immiscible metals form $\mathrm{Au}-\mathrm{Rh}$ surface alloy, which can form a random or an $(1 \times 2)$ ordered phase as a function of the added amount of Au. Figure $2 \mathrm{c}$ image shows the latter unique ordered surface structure appearing on an STM ch-image of $5 \times 5 \mathrm{~nm}^{2}$ and illustrated by a ball model in Fig. 2d. The substrate surface layer prepared in this way consists of gold and rhodium atoms mixed nearly atomically in the topmost layer. More details on the structure of this bimetallic surface can be found in [37]. To learn about the adsorption properties of this bimetallic layer, it was exposed to $5 \mathrm{~L}$ acetaldehyde at $170 \mathrm{~K}$. Following the adsorption HREELS peaks appeared at 500, 840, 920,1120,1200, 1430, 1650, 1730 and at $3000 \mathrm{~cm}^{-1}$ (Fig. 3b.). These features show that acetaldehyde adsorbed molecularly and very possibly as multilayer, evidenced by the $1730 \mathrm{~cm}^{-1}$ loss belonging to $v(\mathrm{CO})$ mode in acetaldehyde molecules in the multilayer phase. Increasing the temperature to $230 \mathrm{~K}$ caused a remarkable attenuation of all peaks and small shifts in peak positions. Interestingly the peaks at around 610 and $750 \mathrm{~cm}^{-1}$ miss also at this temperature, however, the peak at $\sim 1650 \mathrm{~cm}^{-1}$ still exists. These differences on the HREEL spectra suggest a slight discrepancy in the adsorption characteristics, which might be caused not only by the absence of $\eta^{2}-(\mathrm{O}, \mathrm{C})-\mathrm{CH}_{3} \mathrm{CHO}$ but possibly also by the adsorption of acetaldehyde on gold atoms. The stability of these species on the mixed layer is very low compared to the clean $\mathrm{Rh}(111)$ surface considering that at $300 \mathrm{~K}$ only a small indication of adsorbed molecules remains on the HREEL spectra. Although the intensity of these peaks at RT very low, we can recognize the similarity between the nature of this layer and those, which was pictured on the clean surface (e.g.: the peak at $610 \mathrm{~cm}^{-1}$ appeared). Dissociation of these surface intermediates resulted in the formation of adsorbed $\mathrm{CO}$ indicated by the small peaks at $400 \mathrm{~K}$.
HREELS results showed that on the mixed surface layer acetaldehyde adsorbed possibly weakly also on gold atoms. Another part of molecules connected to rhodium atoms but mainly in $\eta^{1}-(\mathrm{O})$ form. HREELS identification, including the lack of characteristic vibrations of $\nu(\mathrm{CO})$ at $230 \mathrm{~K}$ also suggests that the suppressed number of accessible adsorption sites, on which $\eta^{1}-(\mathrm{O})$ form can adsorb caused a reduced tendency toward polymerization.

Summarizing the above results, the behavior of acetaldehyde is obviously controlled by the modified adsorption sites. Namely, upon the formation of $\mathrm{Au}-\mathrm{Rh}$ surface alloy there are only a few rhodium atoms on the surface, which neighbored exclusively by $\mathrm{Rh}$ atoms and form adsorption centers characteristic for a clean $\mathrm{Rh}(111)$ surface. This morphology causes probably that the low coordinated ( $\eta^{1}$ (O)) molecules desorb from the surface without dissociation below $300 \mathrm{~K}$ and only a small amount of molecules remained bonded with two legs to the rhodium, resulting in adsorbed $\mathrm{CO}$ at and above $400 \mathrm{~K}$. Although we have to take into consideration for this scheme that the annealed layer can contain surface carbon remained on the surface as a contamination after dissociation of acetaldehyde, it cannot be the reason for this dramatically different behavior. Whilst on the carbon contaminated surface the carbon decreased the uptake of adsorbed acetaldehyde, nevertheless it facilitated also the $\mathrm{C}-\mathrm{O}$ bond scission and $\mathrm{CO}$ formation with $40-50 \mathrm{~K}$ lower temperature [17].

\subsection{Preparation and Characterization of Boron Nitride Layer on Rh(111) by HREELS}

In the next step we prepared a so called h-BN "nanomesh" layer on $\mathrm{Rh}(111)$ by a CVD method decomposing borazine at $1000 \mathrm{~K}$. The $\mathrm{h}-\mathrm{BN} / \mathrm{Rh}(111)$ system is interesting also 
because it allows preparation of metal clusters with a narrow size distribution [28]. This periodically corrugated super lattice can serve as a template, on which molecules and nanoparticles can be readily adsorbed in a tailored arrangement on atomic length scale $[32,33]$. The preparation method of this monolayer 2D film in our system was described in a previous work in detail [33]. In this study, first we prepared the boron nitride layer on $\mathrm{Rh}(111)$ and titrated with $\mathrm{CO}$ at $300 \mathrm{~K}$. (Fig. 4a, b).

The observed HREEL spectrum (i) in Fig. 4a corresponds well with the literature data, where hexagonal boron nitride layer (h-BN) was prepared and investigated on different single crystal surfaces by HREELS [33, 42]. The peak at $790 \mathrm{~cm}^{-1}$ corresponds to transverse optical (TO) phonon with out-of-plane polarization. The peaks at 1350 and $1510 \mathrm{~cm}^{-1}$ are assigned to phonons with in-plane polarization; the former one is originated from the TO phonon, while the latter one from the longitudinal optical (LO) phonon. Titrating the $2 \mathrm{D}$ film by carbon monoxide $(10 \mathrm{~L})$ at $300 \mathrm{~K}$ caused no change in the spectra (ii) in Fig. 4a. The lack of the substrate metal-CO ( $($ (M-CO)) and $v(\mathrm{CO})$ vibrations (see (iii) curve in Fig. 4 a recorded on $\mathrm{Rh}(111)$ surface saturated by $\mathrm{CO}$ at $300 \mathrm{~K}$ ) is the clear evidence that the h-BN layer covers completely the surface of $\mathrm{Rh}(111)$ and the sticking probability of $\mathrm{CO}$ on $\mathrm{h}-\mathrm{BN}$ layer is very low at room temperature. Figure $4 \mathrm{~b}$ displays HREEL spectra of $\mathrm{h}-\mathrm{BN} / \mathrm{Rh}(111)$ after its exposure to acetaldehyde at $170 \mathrm{~K}$ and annealing at different temperatures. Similarly to carbon monoxide, acetaldehyde does not adsorb on the clear nanomesh layer at his temperature or it was under the detection limit of HREELS. It suggests that we didn't find any sign of substrate metal effect through boron nitride layer toward the adsorption of acetaldehyde.

\subsection{Adsorption of Acetaldehyde on Gold Nanoparticles Prepared on h-BN Covered Rh(111)}

As we have seen above, hexagonal boron nitride proved to be completely inert toward acetaldehyde at $170 \mathrm{~K}$. In this part of our work the effect of deposited gold will be investigated on the adsorption behavior of $\mathrm{CH}_{3} \mathrm{CHO}$ molecule. It seemed to be interesting, partially because the h-BN nanomesh template offers the possibility to produce Au nanoparticles in quasi uniform size and ordering determined by the pore regions of the h-BN mesh [29, 32, 35]. Note, the amplitude of the corrugation of the $\mathrm{BN}$ layer is about $0.55 \AA$, while the periodicity of the hexagonal mesh is $3.2 \pm 0.2 \mathrm{~nm}$. Another interesting aspect of the $\mathrm{Au} / \mathrm{h}-\mathrm{BN} / \mathrm{Rh}(111)$ system is that regarding $\mathrm{h}-\mathrm{BN}$ as an essentially inert support for gold, it is possible to investigate the reactivity of these nanoparticles with a lowest support impact.

LEIS showed that the Au LEIS intensity enhanced sharply at low gold coverage and with the increase of the gold quantity it moderated and did not reach saturation even at 27 MLE of gold. Since LEIS is an extremely surface sensitive method it suggests that at low coverage (up to $\sim 0.2$ MLE) 2D, while at higher coverages 3D Au clusters formed on top of h-BN.

First gold was evaporated onto the h-BN covered $\mathrm{Rh}(111)$ surface at $300 \mathrm{~K}$, followed by exposure of acetaldehyde $(5 \mathrm{~L})$ at $170 \mathrm{~K}$. After the HREEL spectra were recorded at low temperature, we monitored the changes during a stepwise
Fig. 4 a HREEL spectra of the (i) clean and (ii) $\mathrm{CO}$ dosed (10 L) BN/Rh(111) compared to (iii) CO saturated rhodium. $\mathbf{b}$ HREEL spectra taken on after adsorption of $5 \mathrm{~L}$ acetaldehyde on h-BN/Rh(111) surface at $170 \mathrm{~K}$ and followed by annealing at higher temperatures
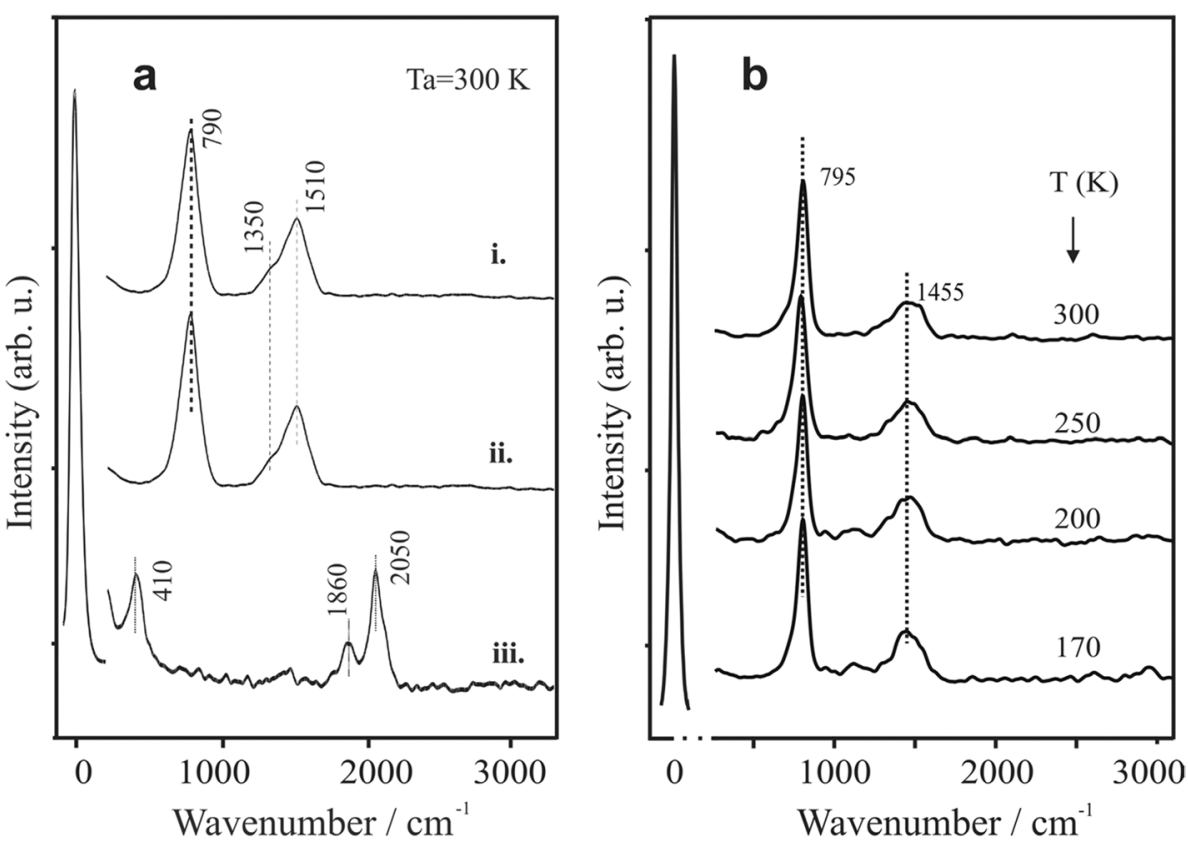
annealing of the sample. At small gold coverages $\left(\Theta_{\mathrm{Au}}<0.3\right.$ MLE) the adsorption of acetaldehyde was barely observable by HREELS (not shown); nevertheless, for increasing amounts of gold the adsorption ability obviously enhanced. At $\Theta_{\mathrm{Au}} \sim 1$ MLE coverage the adsorbed acetaldehyde was clearly detectable; however, the stability of the adsorbed molecules was very low: at $300 \mathrm{~K}$ almost all signs of surface fragments disappeared, only the phonon losses belonging to boron nitride showed up. In Fig. 5a, b we demonstrate the characteristic vibrations of acetaldehyde on gold nanoparticles for 2 MLE (a) and 5 MLE (b) gold coverages.

In the latter case (5 MLE), the h-BN HREELS losses were screened completely by the admetal. Consequently, there were no signs of $\mathrm{BN}$ phonon vibrations before the adsorption of acetaldehyde at $170 \mathrm{~K}$ (not shown). The effects of surface metal on the substrate spectra and the possible screening by inducing image dipoles were previously investigated and described $[43,44]$. Two important observations were made. We experienced that the BN phonon vibrations were hardly observable in HREELS for 5 MLE gold deposition, on the other hand in our LEIS studies the gold signal did not saturate even at coverages above 20-30 MLE. This comparison suggests that the above-mentioned screening effect is rather strong in HREELS, and does not require a complete and continuous gold layer. The reason of this strong effect could be that the first phonon loss at $\sim 790 \mathrm{~cm}^{-1}$ (the TO phonon with out-of-plane polarization) has a dynamic dipole nature (evidenced by off specular measurements) which affected by the gold on the surface.

In both cases ( 2 and 5 MLE) the observed vibrations are characteristic of acetaldehyde; however, the peak positions are slightly different compared to those observed on $\mathrm{Rh}(111)$. Losses appeared at $\sim 850,1120,1180,1350,1425$ and at $2980 \mathrm{~cm}^{-1}$ after $170 \mathrm{~K}$ adsorption of acetaldehyde on 2 MLE gold covered $\mathrm{Rh}(111)$. These features are in good agreement with the loss spectra of acetaldehyde observed on annealed gold layer on clean $\mathrm{Rh}(111)$ (Fig. 3b). There we experienced peaks at $850,920,1100,1160,1380,1450$, a small shoulder at 1650 and broad peak at $3000 \mathrm{~cm}^{-1}$ at $230 \mathrm{~K}$ after multilayer desorption. In harmony with the TPD results of the mentioned analogical experiment from gold covered $\mathrm{BN} / \mathrm{Rh}(111)$ layer, only molecular acetaldehyde desorption (at $\sim 220 \mathrm{~K}$ ) was detected without any sign of dissociation products.

Figure 6a shows the temperature programmed desorption spectra $(\mathrm{m} / \mathrm{e}=44)$ after the adsorption of $5 \mathrm{~L}$ acetaldehyde on $\mathrm{h}-\mathrm{BN} / \mathrm{Rh}(111)$ at increasing gold coverages (iii, iv, v) The first two spectra (i) and (ii) were taken on the clean rhodium and the h-BN covered Rh surface, respectively. It was verified that only the molecular acetaldehyde (the parent molecule) desorption contributed to the intensity of the appeared peaks. On the clean surface we can observe possibly the stabilizing effect of the polymerized form of acetaldehyde ( $\mathrm{T}_{\mathrm{p}}$ around $300 \mathrm{~K}$ ). These polymers strengthen the thermic stability of acetaldehyde molecules in contrast to the lower coverage case where acetaldehyde starts to decompose already at $300 \mathrm{~K}$ to $\mathrm{CO}$ and $\mathrm{H}_{2}$ [17]. On the modified single crystal surfaces we made efforts to detect $\mathrm{CO}, \mathrm{H}_{2}, \mathrm{C}_{2} \mathrm{H}_{5} \mathrm{OH}$ or several other possible reaction products (oligomers too), but it did not succeed. At the same time the adsorbed amount of acetaldehyde gradually increased from close to zero (on $\mathrm{h}-\mathrm{BN} / \mathrm{Rh}(111)$ ) up to saturation value at around 2 MLE of gold coverage (Fig. 6b). After saturation it did not change during our measurement series even when $\mathrm{BN}$ phonon vibrations quasi disappeared from HREEL spectra at around 5 MLE.

There is no sign of polymerization reaction on the HREEL spectra. TPD results at amu 44 shows also only one type of acetaldehyde desorption which does not confirm the production of oligomers on the gold covered h-BN/
Fig. 5 HREEL spectra showing the effect of annealing after adsorption of acetaldehyde $(5 \mathrm{~L})$ at $170 \mathrm{~K}$ on h-BN/ $\mathrm{Rh}(111)$ surface decorated by $\mathbf{a}$ 2 MLE, and b 5 MLE of gold
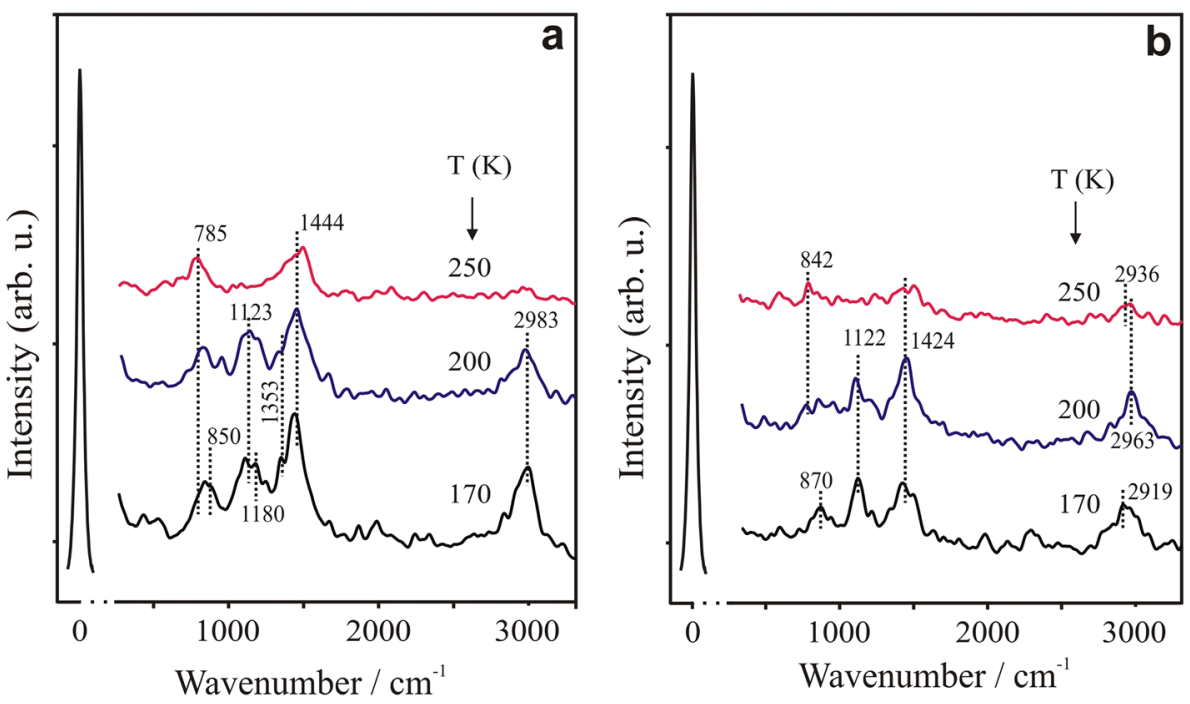
Fig. 6 a TPD spectra recorded after the adsorption of acetaldehyde (5 L) at $170 \mathrm{~K}$ for (i) clean $\mathrm{Rh}(111)$, (ii) h-BN covered $\mathrm{Rh}(111)$ and $\mathrm{Au} / \mathrm{h}-\mathrm{BN} / \mathrm{Rh}(111)$ surfaces of different gold coverages: (iii) 0.3 MLE, (iv) 1 MLE and (v) 2 MLE. b Integrated peak areas of amu 44 (acetaldehyde) as a function of gold coverage on BN/Rh(111). STM cc-images recorded on $\mathbf{c h}$ h-BN/ $\mathrm{Rh}(111)$ surface and Au covered, d 1 MLE and e 2 MLE surfaces $\operatorname{surface}\left(\mathrm{T}_{\mathrm{dep}}=300 \mathrm{~K}\right)$

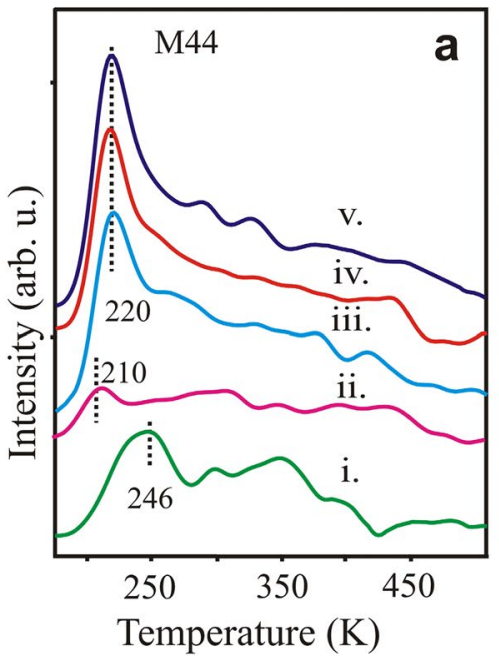

b
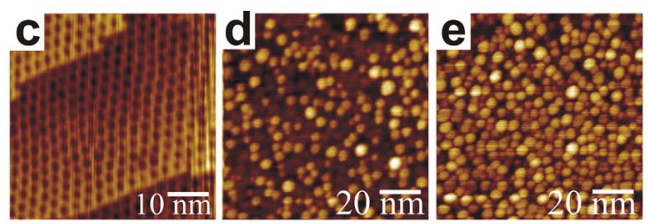

Rh(111) system. Our HREELS and TPD results on different surface layers propose that the possibility of polymerization and the production of oligomers is high only if the interaction between the substrate metal and acetaldehyde is strong enough. Only in that case metal can affect the charge distribution and this way facilitate the connection of the neighboring molecules.

Figure 6c shows a typical STM image of the as-synthesized h-BN layer on $\mathrm{Rh}(111)$ surface. The nanomesh indicates a typical $3.3( \pm 0.2) \mathrm{nm}$ lateral periodicity, which coincides with the superlattice's unit cell's corners. These data are in a good agreement with earlier work [28, 45]. Depositing $1 \mathrm{MLE} \mathrm{Au}$ at $300 \mathrm{~K}$ results in the formation of three-dimensional (3D) nanoparticles on the h-BN film showing wide size distribution, with $1.9 \times 10^{12} \mathrm{~cm}^{-2}$ particle concentration. The highest particles typically consists of 4-5 atomic layers ( $\sim 5 \%$ of the NPs). STM pictures of the investigated adsorption layers $(0,1$ and $2 \mathrm{ML}$ of $\mathrm{Au}$ on h-BN/ Rh(111)) are exhibited on Fig. 6c-e.

In a parallel measurement we followed the changes of the $\mathrm{Au} 4 \mathrm{f}_{7 / 2}$ XPS peak position and the Au $4 \mathrm{f}$ integrated area during deposition of increasing amounts of gold on h-BN/ $\mathrm{Rh}(111)$ at $300 \mathrm{~K}$ (Fig. 7a).

At $\Theta_{\mathrm{Au}}=0.045 \mathrm{MLE}$ the $\mathrm{Au} 4 \mathrm{f}_{7 / 2}$ peak was found at $\sim 83.7 \mathrm{eV}$, while the bulk value is $84.0 \mathrm{eV}$. The rather low binding energy observed at small coverages is attributed to the presence of negative extra charge on Au clusters due to an electron transfer from h-BN (and Rh(111)) to Au nanoparticles, in accordance with previous DFT studies [30-32]. At higher coverages the peak position gradually approaches the bulk value, because the amount of extra charge per $\mathrm{Au}$ atom decreases, and the electronic structure of larger $\mathrm{Au}$ clusters is bulk-like. Interestingly, the amount of acetaldehyde adsorbed on $\mathrm{Au} / \mathrm{h}-\mathrm{BN} / \mathrm{Rh}(111)$ saturates at the same coverage $\Theta_{\mathrm{Au}} \sim 2 \mathrm{MLE}$, where the $\mathrm{Au} 4 \mathrm{f}_{7 / 2}$ binding energy is already very near to the bulk value (Fig. 6b). In a hydrogen chemisorption experiment on $\mathrm{Al}_{2} \mathrm{O}_{3}$ supported gold nanoparticles, published by van Bokhoven et al. a lower hydrogen uptake is measured after increasing the gold particle size by high-temperature reduction [46]. The reason of this similar observation was that the dissociation and adsorption of hydrogen was limited to the gold atoms on corner and
Fig. 7 a Changes in the $\mathrm{Au} 4 \mathrm{f}_{7 / 2}$ XPS peak position and integrated area as a function of gold coverage on h-BN/Rh(111). The Rh 4s contribution was subtracted. The solid lines are to guide the eye. $\mathbf{b}$ Effect of gold coverage on the $\nu(\mathrm{CO})$ HREELS peak after adsorption of $5 \mathrm{~L} \mathrm{CO}$ on clean and gold decorated $\mathrm{Rh}(111)$ at $170 \mathrm{~K}$
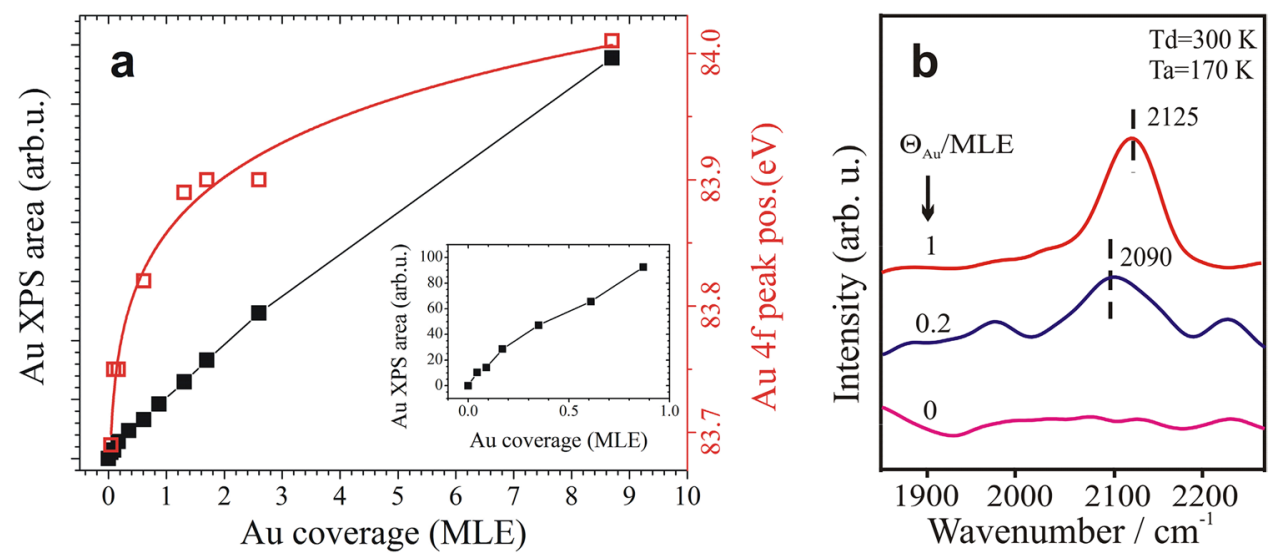
edge positions. In our measurements acetaldehyde adsorption shows very similar behavior-saturation at a certain gold coverage-which strengthens their statement about the active site of gold particles. Please note that edge and corner atoms of gold clusters were suggested to be the active sites also for oxygen and $\mathrm{CO}$ bonding [47]. The slope of the $\mathrm{Au}$ 4f area curve gets smaller above $\Theta_{\mathrm{Au}} \sim 0.2$ MLE confirming the 3D growth of $\mathrm{Au}$ at larger coverages (Fig. 7, inset).

On Fig. $7 \mathrm{~b}$ we presented the effect of gold coverage on the $v(\mathrm{CO})$ HREEL peak after adsorption of $5 \mathrm{~L} \mathrm{CO}$ on clean and gold decorated $\mathrm{Rh}(111)$ at $170 \mathrm{~K}$. These measurements were carried out to gain some information about the charge on Au nanoparticles with the help of $\nu(\mathrm{CO})$ HREELS peak position. The size of nanoparticles and possibly the negative charge on gold particles also influenced the position of the CO HREELS peak after adsorption of $\mathrm{CO}$ on $\mathrm{Au} / \mathrm{h}-\mathrm{BN} /$ $\mathrm{Rh}(111)$. The small shift in $\nu(\mathrm{CO})$ HREELS peak position at this temperature $\sim 170 \mathrm{~K}$ suggests a charge transfer which is resulted -at small size clusters- a negatively charged particles. Peak appeared $2070 \mathrm{~cm}^{-1}$ at 0.2 MLE and it is shifted to higher energies at $~ 1$ MLE. Our explanation is, similarly as it was discussed in the work of McKee earlier [34], that the highly undercoordinated perimeter edge and corner sites bind $\mathrm{CO}$ more strongly than bulk Au surfaces and that the small size Au cluster also contains a sizable negative charge, which is localized on the perimeter atoms. Literature data also deal with the phenomenon of negatively charged gold clusters and with the shift from lower energy value to the higher one tend toward the gas phase value at $2143 \mathrm{~cm}^{-1}$ [48-50].

\section{Conclusions}

In this work we investigated the adsorption properties and reactions of acetaldehyde on clean and gold decorated rhodium and $\mathrm{BN} / \mathrm{Rh}$ (111) surfaces by HREELS and TPD methods. STM and XPS were used to characterize the gold nanoparticles.

- Our results on different surface layers propose that the possibility of polymerization is requires stronger interaction between the substrate metal and acetaldehyde. According to this we observed the sign of oligomers only when clean rhodium terraces are present on the gold modified surfaces.

- The surface alloy formation of gold and rhodium on the clean substrate eliminates the formation of CO. Nevertheless, on an inert BN support increased coverage of gold enhanced the amount of adsorbed aldehyde at low temperature.

- In our measurements acetaldehyde adsorption on gold covered $\mathrm{BN} / \mathrm{Rh}(111)$ shows saturation at a certain gold coverage which suggests that the active sites of gold clusters on h-BN are possibly edge and corner atoms and very likely at small coverages we need to count with a charge transfer between the substrate and gold which is resulted a negatively charged particles and this way gives enhanced reactivity of $\mathrm{Au} / \mathrm{h}-\mathrm{BN} / \mathrm{Rh}(111)$.

Acknowledgements Financial support of this work by the Hungarian Research Development and Innovation Office through grants GINOP2.3.2-15-2016-00013 and NKFIH OTKA K120115 is gratefully acknowledged. The ELI-ALPS project (GINOP-2.3.6-15-2015-00001) is supported by the European Union and co-financed by the European Regional Development Fund. This research was also supported by the European Social Fund in the framework of TÁMOP-4.2.4.A/ 2-11/12012-0001 'National Excellence Program'.

\section{References}

1. Davis JL, Barteau MA (1987) Decarbonylation and decomposition pathways of alcohol's on Pd(111). Surf Sci 187:387-406. https:// doi.org/10.1016/S0039-6028(87)80064-X

2. Davis JL, Barteau MA (1988) The influence of oxygen on the selectivity of alcohol conversion on the Pd(111) surface. Surf Sci 197:123-152. https://doi.org/10.1016/0039-6028(88)90577-8

3. McCabe RW, Dimaggio CL, Madix RJ (1985) Adsorption and reactions of acetaldehyde on $\mathrm{Pt}(\mathrm{S})-[6(111) \mathrm{X}(100)]$. J Phys Chem 89:854-861. https://doi.org/10.1021/j100251a028

4. Mavrikakis M, Barteau MA (1998) Oxygenate reaction pathways on transition metal surfaces. J Mol Catal A Chem 131:135-147. https://doi.org/10.1016/S1381-1169(97)00261-6

5. Raskó J, Kiss J (2005) Adsorption and surface reactions of acetaldehyde on alumina-supported noble metal catalysts. Catal Lett 101:71-77. https://doi.org/10.1007/s10562-004-3752-y

6. Raskó J, Kecskés T, Kiss J (2005) FT-IR and mass spectrometric studies on the interaction of acetaldehyde with $\mathrm{TiO}_{2}$-supported noble metal catalysts. Appl Catal A Gen 287:244-251. https:// doi.org/10.1016/j.apcata.2005.04.004

7. Roberts JM (1990) The atmospheric chemistry of organic nitrates. Atmos Environ 24A:243-287. https://doi.org/10.1016/09601686(90)90108-Y

8. Altshuller AP (1993) Production of aldehydes as primary emissions and from secondary atmospheric reactions of alkenes and alkanes during the night and early morning hours. Atmos Environ Part A Gen Top 27:21-32. https://doi.org/10.1016/09601686(93)90067-9

9. Yee A, Morrison SJ, Idriss H (2000) Reactions of ethanol over M/ $\mathrm{CeO}_{2}$ catalysts. Evidence of carbon-carbon bond dissociation at low temperatures over $\mathrm{Rh} / \mathrm{CeO}_{2}$. Catal Today 63:327-335. https ://doi.org/10.1016/S0920-5861(00)00476-4

10. Mattos LV, Jacobs G, Davis BH, Noronha FB (2012) Production of hydrogen from ethanol: review of reaction mechanism and catalyst deactivation. Chem Rev 112:4094-4123

11. Ferencz Z, Erdohelyi A, Baán K et al (2014) Effects of support and $\mathrm{Rh}$ additive on co-based catalysts in the ethanol steam reforming reaction. ACS Catal 4:1205-1218. https://doi.org/10.1021/ cs500045z

12. De Lima AFF, Colman RC, Zotin FMZ, Appel LG (2010) Acetaldehyde behavior over platinum based catalyst in hydrogen stream generated by ethanol reforming. Int J Hydrog Energy 35:13200 13205. https://doi.org/10.1016/j.ijhydene.2010.09.030 
13. Varga E, Ferencz Z, Oszkó A et al (2015) Oxidation states of active catalytic centers in ethanol steam reforming reaction on ceria based Rh promoted Co catalysts: an XPS study. J Mol Catal A Chem 397:127-133. https://doi.org/10.1016/j.molca ta.2014.11.010

14. Henderson MA, Zhou Y, White JM (1989) Polymerization and decomposition of acetaldehyde on $\mathrm{Ru}(001)$. J Am Chem Soc 111:1185-1193. https://doi.org/10.1021/ja00186a004

15. Davis JL, Barteau MA (1989) Polymerization and decarbonylation reactions of aldehydes on the Pd(111) surface. J Am Chem Soc 111:1782-1792. https://doi.org/10.1021/ja00187a035

16. Houtman CJ, Barteau MA (1991) Divergent pathways of acetaldehyde and ethanol decarbonylation on the $\mathrm{Rh}(111)$ surface. J Catal 130:528-546. https://doi.org/10.1016/0021-9517(91)90133-O

17. Kovács I, Farkas AP, Szitás Á et al (2017) Adsorption, polymerization and decomposition of acetaldehyde on clean and carboncovered Rh(111) surfaces. Surf Sci. https://doi.org/10.1016/j. susc.2017.05.016

18. Karatok M, Vovk EI, Shah AA et al (2016) Erratum: acetaldehyde partial oxidation on the $\mathrm{Au}(111)$ model catalyst surface: $\mathrm{C}-\mathrm{C}$ bond activation and formation of methyl acetate as an oxidative coupling product (Surface Science (2015) 641 (289-293) DOI: 10.1016/j.susc.2015.04.005). Surf Sci 649:152. https://doi. org/10.1016/j.susc.2016.01.011.

19. Meng Q, Shen Y, Xu J et al (2012) Mechanistic understanding of hydrogenation of acetaldehyde on $\mathrm{Au}(111)$ : a DFT investigation. Surf Sci 606:1608-1617. https://doi.org/10.1016/j. susc.2012.06.014

20. Pan M, Flaherty DW, Mullins CB (2011) Low-temperature hydrogenation of acetaldehyde to ethanol on H-precovered $\mathrm{Au}(111)$. J Phys Chem Lett 2:1363-1367. https://doi.org/10.1021/jz200577n

21. Valden M (1998) Onset of catalytic activity of gold clusters on titania with the appearance of nonmetallic properties. Science 281:1647-1650. https://doi.org/10.1126/science.281.5383.1647

22. Haruta M (1997) Size- and support-dependency in the catalysis of gold. Catal Today 36:153-166. https://doi.org/10.1016/S0920 -5861(96)00208-8

23. Haruta M, Daté M (2001) Advances in the catalysis of Au nanoparticles. Appl Catal A Gen 222:427-437. https://doi.org/10.1016/ S0926-860X(01)00847-X

24. Dumbuya K, Cabailh G, Lazzari R et al (2012) Evidence for an active oxygen species on $\mathrm{Au} / \mathrm{TiO}_{2}(110)$ model catalysts during investigation with in situ $\mathrm{X}$-ray photoelectron spectroscopy. Catal Today 181:20-25. https://doi.org/10.1016/j.cattod.2011.09.035

25. Liu L, Zhou Z, Guo Q et al (2011) The 2-D growth of gold on single-layer graphene/ $\mathrm{Ru}(0001)$ : enhancement of $\mathrm{CO}$ adsorption. Surf Sci 605:L47-L50. https://doi.org/10.1016/j.susc.2011.04.040

26. Zhang Y, Zhang Y, Ma D et al (2013) Mn atomic layers under inert covers of graphene and hexagonal boron nitride prepared on Rh(111). Nano Res 6:887-896. https://doi.org/10.1007/s1227 4-013-0365-Z

27. Gotterbarm K, Spath F, Bauer U et al (2015) Reactivity of graphene-supported Pt nanocluster arrays. ACS Catal 5:2397-2403. https://doi.org/10.1021/acscatal.5b00245

28. Corso M (2004) Boron nitride nanomesh. Science 303:217-220. https://doi.org/10.1126/science.1091979

29. Ng ML, Preobrajenski AB, Vinogradov AS, Mårtensson N (2008) Formation and temperature evolution of Au nanoparticles supported on the h-BN nanomesh. Surf Sci 602:1250-1255. https:// doi.org/10.1016/j.susc.2008.01.028

30. Koch HP, Laskowski R, Blaha P, Schwarz K (2011) Adsorption of gold atoms on the h-BN/Rh(111) nanomesh. Phys Rev B 84:1-7. https://doi.org/10.1103/PhysRevB.84.245410

31. Koch HP, Laskowski R, Blaha P, Schwarz K (2012) Adsorption of small gold clusters on the h-BN/Rh(111) nanomesh. Phys Rev B 86:1-7. https://doi.org/10.1103/PhysRevB.86.155404
32. Patterson MC, Habenicht BF, Kurtz RL et al (2014) Formation and stability of dense arrays of Au nanoclusters on hexagonal boron nitride/Rh(111). Phys Rev B 89:1-10. https://doi.org/10.1103/ PhysRevB.89.205423

33. Farkas AP, Török P, Solymosi F et al (2015) Investigation of the adsorption properties of borazine and characterisation of boron nitride on $\mathrm{Rh}(111)$ by electron spectroscopic methods. Appl Surf Sci 354:367-372. https://doi.org/10.1016/j.apsusc.2015.05.060

34. McKee WC, Patterson MC, Huang D et al (2016) CO adsorption on Au nanoparticles grown on hexagonal boron nitride/Rh(111). J Phys Chem C 120:10909-10918. https://doi.org/10.1021/acs. jpcc.6b01645

35. Gubó R, Vári G, Kiss J et al (2018) Tailoring the hexagonal boron nitride nanomesh on $\mathrm{Rh}(111)$ by gold. Phys Chem Chem Phys. https://doi.org/10.1039/C8CP00790J

36. Gazsi A, Koós A, Bánsági T, Solymosi F (2011) Adsorption and decomposition of ethanol on supported Au catalysts. Catal Today 160:70-78. https://doi.org/10.1016/j.cattod.2010.05.007

37. Óvári L, Berkó A, Vári G et al (2016) The growth and thermal properties of Au deposited on $\mathrm{Rh}(111)$ : formation of an ordered surface alloy. Phys Chem Chem Phys 18:25230-25240. https:// doi.org/10.1039/C6CP02128J

38. Furukawa J, Saegusa T, Fujii H et al (1960) Crystalline polyaldehydes. Die Makromol Chem 37:149-152. https://doi.org/10.1002/ macp.1960.020370114

39. Zhao H, Kim J, Koel BE (2003) Adsorption and reaction of acetaldehyde on $\operatorname{Pt}\left(\begin{array}{lll}1 & 1 & 1\end{array}\right)$ and $\operatorname{Sn} / \operatorname{Pt}\left(\begin{array}{lll}1 & 1 & 1\end{array}\right)$ surface alloys. Surf Sci 538:147-159. https://doi.org/10.1016/S0039-6028(03)00602-2

40. Guan Y, Hensen EJM (2013) Selective oxidation of ethanol to acetaldehyde by Au-Ir catalysts. J Catal 305:135-145. https://doi. org/10.1016/j.jcat.2013.04.023

41. Henderson MA, Radloff PL, White JM, Mims CA (1988) Surface chemistry of ketene on $\mathrm{Ru}(001)$. 1 . Surface structures. J Phys Chem 92:11-41. https://doi.org/10.1021/j100325a025

42. Ćavar E, Westerström R, Mikkelsen A et al (2008) A single h-BN layer on $\operatorname{Pt}\left(\begin{array}{lll}1 & 1 & 1\end{array}\right)$. Surf Sci 602:1722-1726. https://doi. org/10.1016/j.susc.2008.03.008

43. Frank M, Wolter K, Magg N et al (2001) Phonons of clean and metal-modified oxide films: an infrared and HREELS study. Surf Sci 492:270-284. https://doi.org/10.1016/S0039-6028(01)01475 $-3$

44. Rokuta E, Hasegawa Y, Suzuki K et al (1997) Phonon dispersion of an epitaxial monolayer film of hexagonal boron nitride on Ni(111). Phys Rev Lett 79:4609-4612. https://doi.org/10.1103/ PhysRevLett.79.4609

45. Berner S, Corso M, Widmer R et al (2007) Boron nitride nanomesh: functionality from a corrugated monolayer. Angew Chem Int Ed 46:5115-5119. https://doi.org/10.1002/anie.200700234

46. Bus E, Miller JT, Van Bokhoven JA (2005) Hydrogen chemisorption on $\mathrm{Al}_{2} \mathrm{O}_{3}$-supported gold catalysts. J Phys Chem B 109:14581-14587. https://doi.org/10.1021/jp051660z

47. Mavrikakis M, Stoltze P, Nørskov JK (2000) Making gold less noble. Catal Lett 64:101-106. https://doi.org/10.1023/A:10190 28229377

48. Yoon B (2005) Charging effects on bonding and catalyzed oxidation of $\mathrm{CO}$ on $\mathrm{Au}_{8}$ clusters on $\mathrm{MgO}$. Science 307:403-407. https ://doi.org/10.1126/science.1104168

49. Chen M, Cai Y, Yan Z, Goodman DW (2006) On the origin of the unique properties of supported Au nanoparticles. J Am Chem Soc 128:6341-6346. https://doi.org/10.1021/ja0557536

50. Sterrer M, Yulikov M, Risse T et al (2006) When the reporter induces the effect: unusual IR spectra of $\mathrm{CO}$ on $\mathrm{Au} 1 / \mathrm{MgO}(001) /$ Mo(001). Angew Chem Int Ed 45:2633-2635. https://doi. org/10.1002/anie.200504473 